NBER WORKING PAPER SERIES

\title{
DISEQUILIBRIUM DYNAMICS WITH INVENTORIES AND ANTICIPATORY PRICE-SETTING
}

\author{
Jerry Green \\ Jean-Jacques Laffont \\ Working Paper No. 453
NATIONAL BUREAU OF ECONOMIC RESEARCH
1050 Massachusetts Avenue
Cambridge MA 02138
February 1980

The research reported here is part of the NBER's research program in Economic Fluctuations. Any opinions expressed are those of the authors and not those of the National Bureau of Economic Research. 


\section{Disequilibrium Dynamics With \\ Inventories and Anticipatory Price-Setting}

\section{ABSTRACT}

This paper studies the sequence of short-run quantity-constrained equilibria of a model with a single storable output, 1abor and money. The durability of output gives rise to inventory fluctuations which influence the course of the equilibria attained.

One special feature of interest is the assumption that prices are not at the level which would equilibrate all markets if there were no stochastic shocks to the economy. With prices frozen at this level, the nature of the realized shocks determines the type of disequilibrium realized and the unintended component of inventory change.

The analysis concentrates on two questions: What is the statistical nature: of the process governing the real wage, output, employment and inventories? And is it possible to test this model against the alternative hypothesis that prices are continually flexible even after the shocks have disturbed the system? We find that although these theories are similar in their qualititive structure, tests can be developed. We also show how the frequencies of different types of quantity-constrained equilibria vary with the stochastic specification. This may shed some insight on why it is commonly believed that some types of disequilibrium phenomena have not been observed.

Jerry Green

National Bureau of Economic Research 1050 Massachusetts Avenue Cambridge, MA :02138. 


\section{Introduction}

The microeconomic foundation of macroeconomics has two fairly wellarticulated paradigms. The neo-classical paradigm maintains that "markets are working": competitive behavior achieves a Pareto optimal outcome under the guidance of the price system. Authorities should interfere as little as possible with this allocation mechanism as long as competitive behavior is maintained. The lack of future and contingent markets pointed out by some has been overcome through the assumption of rational expectations. The Keynesian paradigm on the contrary maintains that "markets are not working". Price rigidities, even with competitive behavior, lead to a misallocation of resources which can be partially remedied by government interventions. This malfunctioning of the price system is explained by informational considerations in the absence of a complete set of markets. The Keynesian paradigm has recently received an extreme formalization in the work of Barro and Grossman [1971], Benassy [1975], Drèze [1975], Malinvaud [1977] and others, through the theoretical construct of fixed-price equilibria.

Although the assumption of fixed prices provides a reasonable explanation of a number of short-run phenomena, such as the multiplier effect or the accelerator principle, it is incomplete in that it fails to provide a theory to determine the level at which prices are fixed. The short-run equilibria attained will be markedly affected by the mechanism used to describe price formation. Via this route, the dynamics of macroeconomic fluctuations are affected by the price change process as well.

The basic assumption of this paper is an attempt to be specific about price formation while retaining a fixed-price, quantity-constrained equili- 
bration in the short-run. We assume that prices are.fixed at the beginning of the period at the level which would be the Walrasian equilibrium if all random factors in the economy had their average levels. We will refer to this as anticipatory pricing. Thus there is a tendency toward market clearing, but short-run disturbances continually keep it from being achieved.

This assumption should be contrasted with that previously used in the disequilibrium literature where measured excess demands were responsible for price changes in the following period. Anticipatory pricing has the advantage of being simpler, especially in the analysis of the stochastic evolution of the system. Furthermore, as the empirical evidence does not provide. support for the hypothesis that excess demand is a principal determinant of price changes, we felt that it was necessary to explore an alternative. Our assumption is somewhat intermediate between the Walrasian (flexible prices) and Keynesian short-run (fixed prices) models, and it has a certain "rational expectations" flavor.*

The second theme of this paper is the role of inventories in macrodynamics -- a topic of long-recognized importance, but one which has not received much attention within the disequilibrium literature.** This is rather ironic, as it is commonplace to assert that the role of such stocks is to cushion the effects of unforeseen fluctuations in demands and supplies, presumably those that are undesired at the prevailing prices. We will

*

It is not, however, a full "rational expectations" model because the rational forecasts of future prices do not enter the current notional demand curves. This will be discussed further in the next section.

$* *$

Blinder-Fischer (1979) have examined flexible price models with tnventories in which the rate of interest is a determinant of the desired level of inventory stocks. They do not address the stochastic nature of the dynamics explicity, whereas this is our principal focus. Blinder (1977) has examined a Keynesian model with inventories and a price dynamics that responds to lagged excess demands. Muellbauer and Portes (1978) have a short-run quantity constrained model with inventories based on explicit maximization by rational agents. They derive the effective demand functions to which our specification can be regarded as a first-order approximation. Although they have obtained many short-run comparative statics results they have not linked the successive quantity-constrained equilibria together in a dynamic analysis. 
analyze how the level of inventories interacts with the level of prices and wages, and how the spillover effects in a fixed-price equilibrium produce certain testable characteristics in macro time series data. We will argue that these can be used to discriminate between a model of the type we study and the analagous flexible-price system.

In Section 1 we set out the basic model and discuss its assumptions. Section 2 derives the short-run quantity-constrained equilibrium as it depends on initial inventory stocks and on the random disturbances within the period. Section 3 presents, for comparison purposes, the analagous results under conditions of full price flexibility after these shocks are realized.

Sections 4 and 5 are the heart of the paper. We first derive the probabilistic nature of the equilibrium under a variety of stochastic specifications. The probabilities of different types of quantity constrained equilibria can be compared under these alternative hypotheses. Then, we use these results to present the dynamics of inventory behavior and the statistical relationships between real wages, inventories and employment. We emphasize the possibility of using this type of analysis to test the disequilibrium hypothesis with anticipatory pricing, against the marketclearing assumptions.

Our theoretical model suggests several lines of empirical investigation. In an appendix, we present some time series evidence on the relationships between the important variables of our system. These are of a preliminary nature and are not designed to test our view of the theory presented. They are nevertheless suggestive particularly because of the unexpectedly large effect of inventories on the real wage. 


\section{The Mode1}

\section{Basic Structure}

The model to be described below has two stores of value, money and inventories, which interact together with the flow demands and supplies on the labor and output markets to determine a short-run equilibrium. Successive short-run equilibria are linked together by the dynamics of inventory movements and the prices and wages which result from them.

Before deriving the stochastic structure of this dynamic disequilibrium process, we should discuss the nature of the model -- and especially the central role to be played by inventories and the price formation mechanism. Inventories are accumulated as the result of an excess of output over sales to consumers. " It is assumed that such sales of output are entirely consumed; the inventories are owned exclusively by firms. Similarly, money balances are held only by households. They are used to finance purchases of goods in excess of labor income. Both inventory levels and real money balances are desired because they provide the individual decision makers with flexibility in case they are unable to fully execute their desired transactions. In the aggregate, therefore, we will assume a positive desired inventory stock and that the level real balances enters the demand and supply function of households. *****

* Blinder (1978) offers an extensive discussion of inventories as inputs, but finally assumes that their role as residual output is dominant, as we do.

** It should be mentioned, or rather confessed, at the outset, that this formulation does not treat the role of firms' profits and their imputation back to the household sector in a consistent fashion. Implicitly, any money balances accumulated by firms are immediately transferred back to the household sector, but these profits are not anticipated at all. Inder competitive conditions -that is with many households, each of whom treats profit income as independent of their own actions -- this formalization is consistent with a $100 \%$ profits tax and a monetary policy designed to keep the nominal stock of money constant. $\star * *$

Rational agents should recognize the influence of firms' inventories on their future profit income, but we have neglected that as well. In future work we will addriss savings and asset markets, particularly the relation

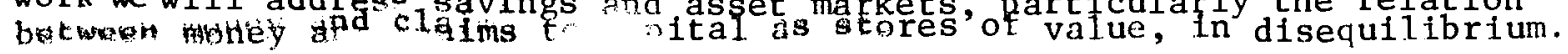


Because firms wish to maintain some inventories, part of planned production may be intended for Inventory accumulation. An increase in inventory stocks is not, by itself, enough to indicate that firms could not sell all they wanted to. The actual variation in these stocks is a composite of the intended and unintended changes.

. The price-setting process is conceptualized as follows: Time is measured in discrete intervals. The level of inventories is known at the beginning of each period. Further the expected values of demands and supplies of goods and labor as functions of the nominal prices and the stocks of money and inventories are known. These functions may differ from their expected values because of unforeseeable, random events. Prices are set during the period at the values that would clear the market if these expectations were all realized. During the period they remain rigid, and it is this inflexibility which is the source of the disequilibrium dynamics that we will be studying. Obviously the extreme nature of this process is not to be justified on the grounds that it precisely represents the workings of any economy. Moreover, the length of the period affects the extent of the disequilibrium generated by the temporarily frozen price levels in a serious way, and no one choice can really be defended. Nevertheless we believe that the study of this model can provide useful insights and that it can be viewed as an approximation to an actual economy in which a variety of disequilibrium adjustments are taking place simultaneously. After giving an algebraic statement of the model, we will return to such a discussion. 


\section{Mathematical Specification}

In order to make the model tractable we will impose a linear structure on the supply and demand functions. Following Barro - Grossman (1971) and Malinvaud (1977) the amount by which an agent is constrained below his desired level of purchase or sale in one market enters into the determination of his desired trade in the other market. These "spillover effects" are also assumed to be linear. For the production sector we have

$$
x_{t}^{s}=\alpha_{0}\left(s_{t}-\bar{s}\right)+\alpha_{1} p_{t}+\alpha_{2} w_{t}+a\left(\ell_{t}-\ell_{t}^{d}\right)+\varepsilon_{t}^{1}
$$

$$
e_{t}^{d}=\gamma_{0}\left(s_{t}-\bar{s}\right)+\gamma_{1} p_{t}+\gamma_{2} w_{t}+c\left(x_{t}-x_{t}^{s}\right)+\varepsilon_{t}^{3}
$$

where

$$
\begin{aligned}
& x_{t}^{s}=\text { desired level of supply (i.e. of actual sales) to the } \\
& \text { household sector } \\
& e_{t}^{d}=\text { desired level of labor demand } \\
& p_{t}, w_{t}=\text { logarithm of price level and wage rate, respectively } \\
& x_{t}, l_{t}=\text { actual, market-determined sales and empioyment } \\
& s_{t}=\text { inventory stocks at the start of the period } \\
& \bar{s}_{t}=\text { desired level of inventory stocks in a steady-state } \\
& \varepsilon_{t}^{1}, \varepsilon_{t}^{3}=\text { random errors }
\end{aligned}
$$

al1 in period $t$.

One should note that if the firm is interested in maximizing the present value of its profits, expressed in real terms in units of output, it follows that 
(1.3) $\quad \alpha_{1}=-\alpha_{2}>0$

and

$$
\text { (1.4) } \quad \gamma_{1}=-\gamma_{2}>0
$$

Suppose that the marginal product of labor is $g>0$, and that it is regarded as a constant over the range of variation we are considering. It is natural to assume that if the sales are rationed by an additional unit, that is if $x_{t}<x_{t}^{s}$ and $x_{t}$ decreases by one unit, then the decreased demand for labor would be such as to decrease actual output by less than one unit, the residual being used for inventory accumulation. Thus we have

$$
\text { (1.5) } 0<c<1 / g
$$

This can be derived from the second order conditions for the firm's problem. Similarly an extra unit constraint on labor demand should be absorbed partially by a reduction in inventory stocks and partially by a decrease in the volume of goods offered for sale.

(1.6) $0<\mathrm{a}<\mathrm{g}$.

Finally, an extra unit of inventory should result in a mixture of sales increase and labor demand decrease. However, since the adjustment made within one period is only partial,

$$
\text { (1.7) } \quad \alpha_{0}-g \gamma_{0}<1
$$

with

$$
\text { (1.8) } \quad \alpha_{0}>0, \gamma_{0}<0
$$


(For a formal derivation of similar restrictions see Blinder and Fischer(1978)).

For households we have the behavioral relatfons

(1.9) $\quad x_{t}^{d}=\beta_{1} p_{t}+\beta_{2} w_{t}+b\left(\ell_{t}-e_{t}^{s}\right)+\varepsilon_{t}^{2}$

(1.10) $\left.\quad e_{t}^{s}=\delta_{1} p_{t}+\delta_{2} w_{t}+d^{\left(x_{t}\right.}-x_{t}^{d}\right)+\varepsilon_{t}^{4}$

where $x_{t}^{d}$ and $e_{t}^{s}$ are the demand for goods and offer of labor services respectively.

The theory of household behavior differs from the theory for firms because it is the households who hold money balances. Since we will treat the case of a constant money stock throughout, nominal prices and price expectations are sufficient to specify the level of real balances. Because we take the view that the unit of time is rather short compared with the planning horizon of the household, the principal determinant of the households' demand for real balances is its expectation of future prices and wages. It will be shown below that prices in any period depend solely on the predetermined inventory level. Moreover, because inventories will follow astationary Markov process, in the long run the average level of prices and wages is known. Under these conditions the price and wage expectations relevant to demands at any moment in time can, to a first approximation, be regarded as exogenous and fixed. Thus (1.9) and (1.10) include prices and wages because of their short run effects, but need include neither expectations nor money balances explicitly.*

The standard theory of consumer behavior over time would give us a zero degree homogeneity of market behavior in prices and wages for the

Since $\left(p_{t}, w_{t}, s_{t}\right)$ will follow a Markov process, future values of ( $p_{t}, w_{t}$ ) can be forecasted from present ones. Thus prices and wages enter (1.9) and (1.10) in their role as predictors as well as through intertemporal substitution effects. 
current and all future periods. If nominal prices in the short run were to increase, the constancy of long-run expectations would imply a negative "real-balance effect".

Assuming that consumption and leisure are all normal goods, we have that

(1.11) $\quad \beta_{1}+\beta_{2}<0$

$(1.12) \quad \delta_{1}+\delta_{2}>0$

Further,

(1.13) $\quad \beta_{1}<0, \beta_{2}>0$

follows from standard considerations of demand theory. The signs and magnitudes of $\delta_{1}$ and $\delta_{2}$ cannot be derived from such considerations; but we will sometimes assume that they are both relatively small, as empirical evidence suggests.

Using these conditions to simplify the system we have that

$$
x_{t}^{s}=\alpha_{0}\left(s t_{t}-\bar{s}\right)+\alpha_{1}\left(p_{t}-w_{t}\right)+a\left(l_{t}-l_{t}^{d}\right)+\varepsilon_{t}^{1}
$$

$(+)$

(+)

$$
x_{t}^{d}=\beta_{1} p_{t}+\beta_{2} w_{t}+b\left(l_{t}-l_{t}^{s}\right)+\varepsilon_{t}^{2}
$$

$(-)$

$(+)$

$(+)$

$$
e_{t}^{d}=\gamma_{0}\left(s s_{t}-\bar{s}\right)+\gamma_{1}\left(p_{t}-w_{t}\right)+c\left(x_{t}-x_{t}^{s}\right)+\varepsilon_{t}^{3}
$$

$$
\ell_{t}^{s}=\delta_{1} p_{t}+\delta_{2} w_{t}+d\left(x_{t}-x_{t}^{d}\right)+\varepsilon_{t}^{4}
$$

$$
(-) \quad(+) \quad(+)
$$

where the signs indicate the assumptions being made on the indicated parameter.

Finally, to close the model, we make the standard disequilibrium theoretic assumption that actual quantities are determined by the "short- 
side" of each market:

$$
\begin{aligned}
& (1.18) \quad x_{t}=\min \left(x_{t}^{d}, x_{t}^{d}\right) \\
& (1.19) \quad \ell_{t}=\min \left(\ell_{t}^{d}, e_{t}^{s}\right) .
\end{aligned}
$$

While these quantity adjustment rules can be criticized on several grounds, they have the great advantage of providing analytical tractibility. They also lead to a theory that can, in principal, be tested against a corresponding equilibrium theory.

The basic assumption of our model is that $p_{t}$ and $w_{t}$ are set in advance at the level that would clear the market if there were zero errors in each of the behavioral equations. Defining these levels as $\mathrm{P}_{t}^{*}$, $\mathrm{w}_{t}^{*}$ we have,

$$
\begin{aligned}
& \alpha_{0}\left(s_{t}-\bar{s}\right)+\alpha_{1}\left(p_{t}^{*}-w_{t}^{*}\right)=\beta_{1} p_{t}^{*}+\beta_{2} w_{t}^{*} \equiv x_{t} \\
& \gamma_{0}\left(s_{t}-\bar{s}\right)+\gamma_{1}\left(p_{t}^{*}-w_{t}^{*}\right)=\delta_{1} p_{t}^{*}+\delta_{2} w_{t}^{*} \equiv L_{t}
\end{aligned}
$$

yielding

(1.22) $\quad \mathrm{p}_{t}^{*}=\left(\mathrm{s}_{\mathrm{t}}-\overline{\mathrm{s}}\right)\left[\frac{\alpha_{0}\left(\delta_{2}+\gamma_{1}\right)-\gamma_{0}\left(\beta_{2}+\alpha_{1}\right)}{\left(\beta_{1}-\alpha_{1}\right)\left(\delta_{2}+\gamma_{1}\right)-\left(\delta_{1}-\gamma_{1}\right)\left(\beta_{2}+\alpha_{1}\right)}\right]$

(1.23) $\quad w_{t}^{*}=\left(s_{t}-\bar{s}\right)\left[\frac{\gamma_{0}\left(\beta_{1}-\alpha_{1}\right)-\alpha_{0}\left(\delta_{1}-\gamma_{1}\right)}{\left(\beta_{1}-\alpha_{1}\right)\left(\delta_{2}+\gamma_{1}\right)-\left(\delta_{1}-\gamma_{1}\right)\left(\beta_{2}+\alpha_{1}\right)}\right]$

Let

$$
\Delta=\left(\beta_{1}-\alpha_{1}\right)\left(\delta_{2}+\gamma_{1}\right)-\left(\delta_{1}-\gamma_{1}\right)\left(\beta_{2}+\alpha_{1}\right) \equiv \gamma_{1}\left(\beta_{1}+\beta_{2}\right)-\alpha_{1}\left(\delta_{1}+\delta_{2}\right)+\beta_{1} \delta_{2}-\delta_{1} \beta_{2}
$$

Prices are fixed at these levels at the beginning of the period, then the values of random variables $\left(\varepsilon_{t}^{1}, \varepsilon_{t}^{2}, \varepsilon_{t}^{3}, \varepsilon_{t}^{4}\right)$ are realized so that ( $p_{t}^{*}$, $w_{t}^{*}$ ) is not a Walrasian equilibrium price system in general. We study a fixed- 
price equilibrium in which the quantities $x_{t}$ and $\ell_{t}$ serve as the equilibrating variables. That is, one can imagine sales and employment varying until, at their equilibrium levels, the system of equations given by (1.14) - (1.19) is satisfied.

\section{Discussion of the Model}

Although there is no firm microeconomic foundation for our assumption that prices are fixed at their anticipated Walrasian levels, and are then frozen there for the ensuing period, we had several reasons for adopting such a formulation. It is clear that in any macroeconomic model that deals with sufficiently short time periods, neither the assumption of perfect price flexibility nor the assumption of quantity flexibility would be reasonable. The world is in continual disequilibrium to a much greater extent then efther pure formalization admits. In this paper we will emphasize quantities as the equilibrating variables, while recognizing that this is but one extreme among a continuum of possibilities. In any context where one adopts either the strict price-flexibility or quantityflexibility paradigms, the length of the period in question makes a big difference as to whether the model does or does not approximate the reality.

Our choice of the price level at the anticipated Walrasian equilibrium should be compared with several other possibllities. Most of the literature on disequilibrium macroeconomics ${ }^{*}$ has assumed that prices adjust from their lagged values according to the lagged value of excess demand. In our model,

In the econometrics literature, both adjustment of prices to past excess demands and partial adjustment to current excess demands have been used (see for example Fair and Jaffee [1974], Laffont and Garcia [1977]. In the economic theory literature adjustment to past excess demands has been the rule (see Honkapohja [1979], Laroque (forthcoming)). 
one of the impacts of previous disequilibria is to alter the level of stocks. Therefore prices in our model will be higher after a period of excess demand for goods, as in these systems. The analogous property does not apply to the wage rate, as labor services are not durable, nor is there explicitly intertemporal substitution of labor for leisure over individuals' lifetimes.

These two price adjustment hypotheses are hard to compare on empirical grounds. One reason why prices are likely to appear responsive to lagged excess demands is the auto correlation of errors. However, such an observation would not contradict the basic motivation for having an anticipatory pricing process. For contractual reasons, or because of the difficulty of monitoring and responding to the current state of disequilibrium, the firms and workers might try to use pricing rules designed to approximate an efficient market-clearing system.

In planned economies there is some evidence that prices are set so as to approximate equilibria that are forecasted. This may provide a justification of our anticipatory pricing assumption in modeling such systems.

To take one alternative, we might suppose that prices are set at the mathematical expectation of the ex post equilibrium. The difficulty with this assumption is that the bias of these prices away from $\phi_{t}^{*}$, $w_{t}^{*}$ ) depends upon the distribution of the disturbances $\varepsilon_{t}$. Therefore ${ }^{t}$ complicated pair of non-linear equations would have to be solved to find the prices and wages, in contrast to the simple system (1.20) - (1.21).

Another price-setting mechanism is that prices are only incompletely flexible within the period. They end up somewhere between their lagged values and the location of the market-clearing equilibrium. This amounts to an adjustment in response to current, rather than lagged, excess demands. This hypothesis is attractive in that the length of the period can be reflected in the specification of the adjustment speed. Unfortunately we were unable to obtain tractable dynamic results. 


\section{The short-run equilibrium under quantity rationing}

With $p_{t}^{*}$ and $w_{t}^{*}$ fixed by (1.22) and (1.23) and after the realization of $\varepsilon_{t}^{1}, \varepsilon_{t}^{2}$, $\varepsilon_{t}^{3}, \varepsilon_{t}^{4}$, the system $(1.14)-(1.19)$ can be solved. It is easiest to describe the dependence of the solution on the $\varepsilon^{\prime} s$ by separately analyzing the four cases in which they are linear.

Regime 1: Excess supply in both markets : Keynesian Unemployment

$(2.1)$

$$
x_{t}^{s}>x_{t}^{d}=x_{t}
$$

$$
\ell_{t}^{s}>\ell_{t}^{d}=l_{t}
$$

We can rewrite $(1.14)-(1.17)$ as

$$
\left[\begin{array}{cccc}
1 & 0 & 0 & 0 \\
0 & 1 & -b & b \\
c & -c & 1 & 0 \\
0 & 0 & 0 & 1
\end{array}\right]\left[\begin{array}{c}
x_{t}^{s} \\
x_{t}^{d} \\
e_{t}^{d} \\
e_{t}^{s}
\end{array}\right]=\left[\begin{array}{l}
x_{t}+\varepsilon_{t}^{1} \\
x_{t}+\varepsilon_{t}^{2} \\
L_{t}+\varepsilon_{t}^{3} \\
L_{t}+\varepsilon_{t}^{4}
\end{array}\right]
$$

yielding

$$
\begin{aligned}
& x_{t}^{s}=x_{t}+\varepsilon_{t}^{1} \\
& x_{t}^{d}=x_{t}=x_{t}+\frac{-b c \varepsilon_{t}^{1}+\varepsilon_{t}^{2}+b\left(\varepsilon_{t}^{3}-\varepsilon_{t}^{4}\right)}{1-b c} \\
& \ell_{t}^{d}=\ell_{t}=L_{t}+\frac{-c\left(\varepsilon_{t}^{1}-\varepsilon_{t}^{2}\right)+\varepsilon_{t}^{3}-b c \varepsilon_{t}^{4}}{1-b c} \\
& \ell_{t}^{s}=L_{t}+\varepsilon_{t}^{4}
\end{aligned}
$$


Regime 2: Excess supply on the good market and excess demand on the labor market : Under Consumption

$$
\text { market : Under Consumption }
$$$$
x_{t}^{s}>x_{t}^{d}=x_{t}
$$$$
\ell_{t}^{d}>\ell_{t}^{s}=\ell_{t}
$$

The structural equations are

$$
\left[\begin{array}{cccc}
1 & 0 & a & -a \\
0 & 1 & 0 & 0 \\
c & -c & 1 & 0 \\
0 & 0 & 0 & 1
\end{array}\right]\left[\begin{array}{l}
x_{t}^{s} \\
x_{t}^{d} \\
e_{t}^{d} \\
e_{t}^{s}
\end{array}\right]=\left[\begin{array}{l}
x_{t}^{*}+\varepsilon_{t}^{1} \\
x_{t}+\varepsilon_{t}^{2} \\
L_{t}+\varepsilon_{t}^{3} \\
L_{t}+\varepsilon_{t}^{4}
\end{array}\right]
$$

ylelding

$(2.4)$

$$
\begin{aligned}
& x_{t}^{s}=x_{t}+\frac{\varepsilon_{t}^{1}-a c \varepsilon_{t}^{2}+a\left(-\varepsilon_{t}^{3}+\varepsilon_{t}^{4}\right)}{1-a c} \\
& x_{t}^{d}=x_{t}=X_{t}+\varepsilon_{t}^{2} \\
& e_{t}^{d}=L_{t}+\frac{-c\left(\varepsilon_{t}^{1}-\varepsilon_{t}^{2}\right)+\varepsilon_{t}^{3}-a c \varepsilon_{t}^{4}}{1-a c} \\
& e_{t}^{s}=L_{t}=B_{t}+\varepsilon_{t}^{4}
\end{aligned}
$$

Regime 3: Excess demand in both markets: Repressed inflation

$$
\begin{aligned}
& x_{t}^{d}>x_{t}^{s}=x_{t} \\
& e_{t}^{d}>e_{t}^{s}=l_{t}
\end{aligned}
$$


$-15-$

The structural equations are:

$$
\left[\begin{array}{cccc}
1 & 0 & a & -a \\
0 & 1 & 0 & 0 \\
0 & 0 & 1 & 0 \\
-d & d & 0 & 1
\end{array}\right]\left[\begin{array}{l}
s \\
x_{t} \\
x_{t} \\
e_{t}^{d} \\
e_{t}^{s}
\end{array}\right]=\left[\begin{array}{l}
x_{t}+\varepsilon_{t}^{1} \\
x_{t}+\varepsilon_{t}^{2} \\
L_{t}+\varepsilon_{t}^{3} \\
L_{t}+\varepsilon_{t}^{4}
\end{array}\right]
$$

yielding

$$
\begin{aligned}
x_{t}^{s} & =x_{t}=x_{t}+\frac{\varepsilon_{t}^{1}-a d \varepsilon_{t}^{2}+a\left(-\varepsilon_{t}^{3}+\varepsilon_{t}^{4}\right)}{1-a d} \\
x_{t}^{d} & =x_{t}+\varepsilon_{t}^{2}
\end{aligned}
$$

2.6)

$$
\begin{aligned}
& \ell_{t}^{d}=L_{t}^{*}+\varepsilon_{t}^{3} \\
& \ell_{t}^{s}=l_{t}=L_{t}+\frac{d\left(\varepsilon_{t}^{1}-\varepsilon_{t}^{2}\right)-a d \varepsilon_{t}^{3}+\varepsilon_{t}^{4}}{1-a d}
\end{aligned}
$$

Regime 4: Excess demand on the good market and excess supply on the labor market : Classical Unemployment

$$
x_{t}^{d}>x_{t}^{s}=x_{t}
$$

(2.7)

$$
\ell_{t}^{s}>\ell_{t}^{d}=\ell_{t}
$$

we have 


$$
\left[\begin{array}{cccc}
1 & 0 & 0 & 0 \\
0 & 1 & -b & b \\
0 & 0 & 1 & 0 \\
-d & d & 0 & 1
\end{array}\right]\left[\begin{array}{l}
x_{t}^{s} \\
x_{t}^{d} \\
e_{t}^{d} \\
e_{t}^{s}
\end{array}\right]=\left[\begin{array}{l}
x_{t}+\varepsilon_{t}^{1} \\
x_{t}+\varepsilon_{t}^{2} \\
L_{t}+\varepsilon_{t}^{3} \\
L_{t}+\varepsilon_{t}^{4}
\end{array}\right]
$$

ylelding

$$
\begin{aligned}
& x_{t}^{s}=x_{t}=x_{t}+\varepsilon_{t}^{1} \\
& x_{t}^{d}=x_{t}+\frac{-b d \varepsilon_{t}^{1}+\varepsilon_{t}^{2}+b\left(\varepsilon_{t}^{3}-\varepsilon_{t}^{4}\right)}{1-b d}
\end{aligned}
$$

$$
\begin{aligned}
& \ell_{t}^{d}=l_{t}=L_{t}+\varepsilon_{t}^{3} \\
& \ell_{t}^{s}=L_{t}+\frac{d\left(\varepsilon_{t}^{1}-\varepsilon_{t}^{2}\right)-b d \varepsilon_{t}^{3}+\varepsilon_{t}^{4}}{1-b d}
\end{aligned}
$$

Within each regime we can study the stability of the natural quantity adjustment processes

$$
\begin{aligned}
& x_{t}=h_{1}\left(\min \left(x_{t}^{d}, x_{t}^{s}\right)-y_{t}\right) \\
& \ell_{t}=h_{2}\left(\min \left(\ell_{t}^{d}, \ell_{t}^{s}\right)-\ell_{t}\right)
\end{aligned}
$$

where $h_{1}$ and $h_{2}$ are sign-preserving functions. It follows from an examination of the linear systems $(2.2),(2.4),(2.6)$ and $(2.8)$, that this dynamic adjustment process would be locally stable provided that

$(2.10)$

$$
\begin{aligned}
& 1-b c>0 \\
& 1-a c>0 \\
& 1-a d>0 \\
& 1-b d>0
\end{aligned}
$$


For example, suppose that an equilibrium in Regime 1 were disturbed by a small upward perturbation in sales of $\Delta x_{t} \cdot$ This would produce a lower level of constraint in the supply of goods and hence an increase of $c \Delta x_{t}$ in the demand for labor. The change would give rise to more demand for goods by $b c \Delta x_{t}$. Summing up the induced increase in demands, stability requires $1-b c>0$. Now, when we consider the entire equation system in which these regimes are juxtaposed it has been shown by Gourleroux, Laffont and Monfort [1978] that the existence and uniqueness of the quantity-constrained solution is implied when these local stability properties hold within each regime.

Let us compute the constraints on the $\varepsilon^{\prime} s$ such that the realized values of demands and supplies satisfy the definition of each of the regimes. For example, assuming that we are in Regime $1, x_{t}^{d}, x_{t}^{s}, \ell_{t}^{d}, \ell_{t}^{s}$ are given by (2.2) and if they are to satisfy (2.1) we must have that

$$
\varepsilon_{t}^{1}-\varepsilon_{t}^{2}-b\left(\varepsilon_{t}^{3}-\varepsilon_{t}^{4}\right)>0
$$$$
c\left(\varepsilon_{t}^{1}-\varepsilon_{t}^{2}\right)-\left(\varepsilon_{t}^{3}-\varepsilon_{t}^{4}\right)>0
$$

and conversely, if (2.1D) is satisfled, then the solution to (2.2) will lie in Regime 1. Pursuing this method for the other regimes we find that they are realized if the $\varepsilon^{\prime} s$ lie in the following regions:

Regime 2

$$
\varepsilon_{t}^{1}-\varepsilon_{t}^{2}-a\left(\varepsilon_{t}^{3}-\varepsilon_{t}^{4}\right)>0
$$

$$
c\left(\varepsilon_{t}^{1}-\varepsilon_{t}^{2}\right)-\left(\varepsilon_{t}^{3}-\varepsilon{ }_{t}^{4}\right)<0
$$

Regime 3

$$
\varepsilon_{t}^{1}-\varepsilon_{t}^{2}-a\left(\varepsilon_{t}^{3}-\varepsilon_{t}^{4}\right)<0
$$

$$
\mathrm{d}\left(\varepsilon_{t}^{1}-\varepsilon_{t}^{2}\right)-\left(\varepsilon_{t}^{3}-\varepsilon_{t}^{4}\right)<0
$$


Regime $4\left(\varepsilon_{t}^{1}-\varepsilon_{t}^{2}\right)-b\left(\varepsilon_{t}^{3}-\varepsilon_{t}^{4}\right)<0$

$(2.14)$

$$
\mathrm{d}\left(\varepsilon_{\mathrm{t}}^{1}-\varepsilon_{\mathrm{t}}^{2}\right)-\left(\varepsilon_{\mathrm{t}}^{3}-\varepsilon_{\mathrm{t}}^{4}\right)>0
$$

A direct comparison of (2.11) - (2.14) reveals that, under the conditions (2.10), these regions form a partition of the space of all $\left(\varepsilon_{t}^{1}, \varepsilon_{t}^{2}, \varepsilon_{t}^{3}, \varepsilon_{t}^{4}\right)$ vectors .

Let

$$
v_{t}^{1}=\varepsilon_{t}^{1}-\varepsilon_{t}^{2}
$$

(2.15)

$$
v_{t}^{2}=\varepsilon_{t}^{3}-\varepsilon_{t}^{4}
$$

One can see directly that the four different regimes can be represented in the $\left(v_{t}^{1}, v_{t}^{2}\right)$ space (see Figure 1, next page). 
Figure 1

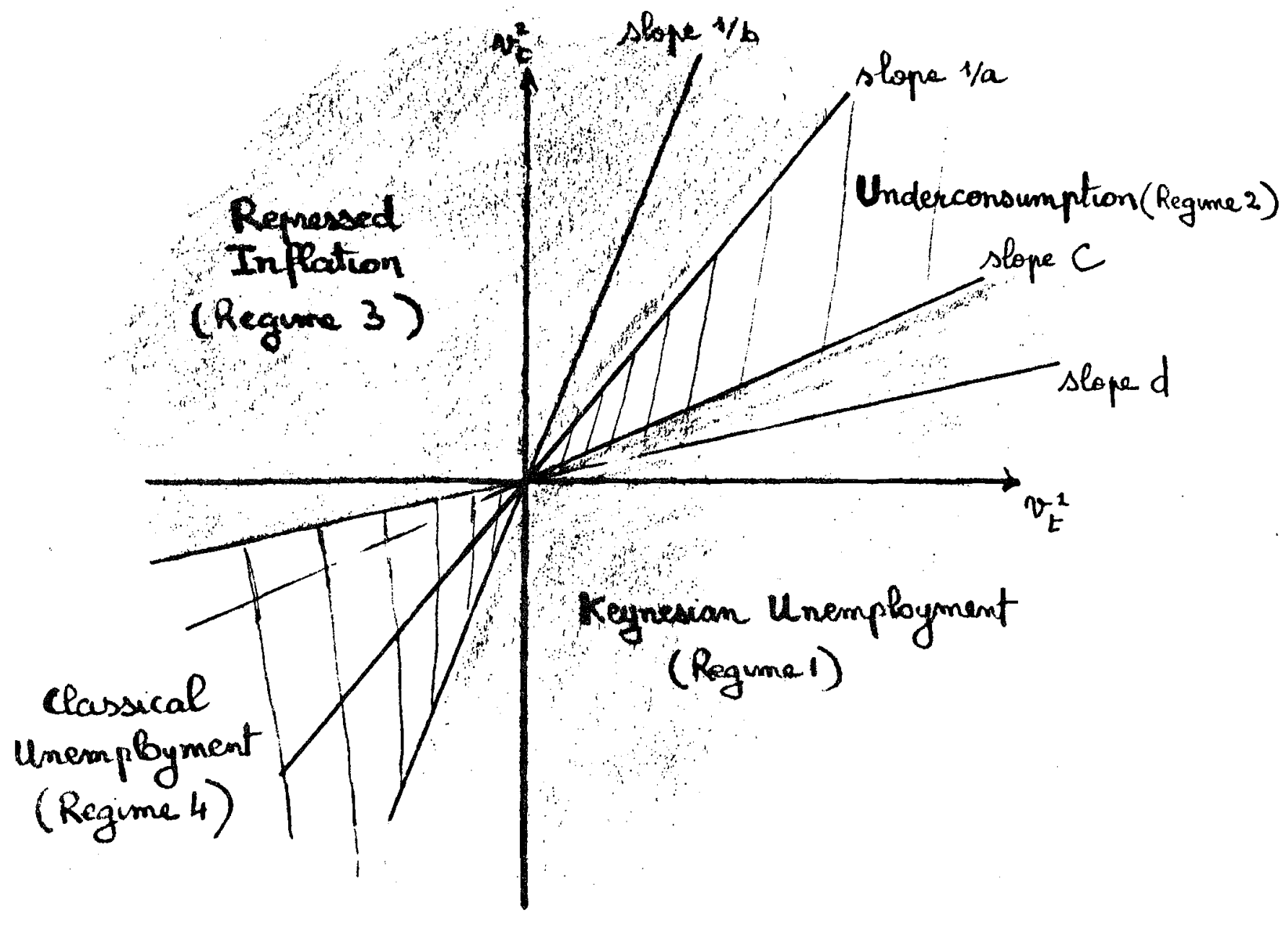

In this figure we consider the case $a>b, c>d$ which will be motivated in the next section. 


\section{Short-run equilibria with price flexibility}

For future reference, it is useful at this point to derive the prices, wages and equilibrium quantities that would arise if prices and wages were to adjust so as to clear both markets after the realization of the disturbances. Setting (1.14) equal to (1.15), (1.16) equal to (1.17) and ignoring all the terms involving spillover effects we can derive the following expression for the equilibrium real wage:

$$
\begin{aligned}
\Delta \cdot\left(w_{t}^{*}-p_{t}^{*}\right)=\left[\gamma_{0}\left(\beta_{1}+\beta_{2}\right)\right. & \left.+\alpha_{0}\left(\delta_{1}+\delta_{2}\right)\right]\left(s_{t}-\bar{s}\right) \\
& +\left(\beta_{1}+\beta_{2}\right) v_{t}^{2}-\left(\delta_{1}+\delta_{2}\right) v_{t}^{1}
\end{aligned}
$$

where $\Delta$ is given by $(1.24)$. Equilibrium employment, and hence output, are given by

$$
\begin{aligned}
\Delta \ell_{\mathbf{t}}=\left\{\gamma_{0}\left[\delta_{2}\left(\beta_{1}-\alpha_{1}\right)-\delta_{1}\left(\beta_{2}+\alpha_{1}\right)\right]+\alpha_{0} \gamma_{1}\left[\delta_{1}+\delta_{2}\right]\right\}\left(s_{t}-\bar{s}\right) \\
+\Delta \varepsilon_{t}^{4}+\left(\delta_{1}+\delta_{2}\right) \gamma_{1} v_{t}^{1}-\left[\delta_{1}\left(\beta_{2}+\alpha_{1}\right)-\delta_{2}\left(\beta_{1}-\alpha_{1}\right)\right] v_{t}^{2}
\end{aligned}
$$

The stability condition on the Walrasian price adjustment process where wages respond to excess demand in the labor market and prices to excess demand in the goods market implies that $\Lambda<0$. These stability conditions will be satisfied whenever $\delta_{1}$ and $\delta_{2}$ are relatively small (see the right hand side of (1.24)). The comparative statics of the equilibrium model with respect to inventories and shocks can be derived in a straightforward way. It may be seen that the real wage responds negatively to inftial inventories, positively to shocks that increase the excess demand for labor, and positively to shocks that increase the excess demand for goods. These comparative statics are in accordance with one's intuition that inftial inventories are a substitute for labor inputs in the short-run production process. 
4. Probabilistic structure of the short-run quantity constrained equilibria

The principal question answered in this section is how the stochastic specification of the model induces the probabilities that each of the four types of quantity-constrained equilibria will arise. In complete generality, the symmetry with which our model treats the goods and labor markets makes it impossible to derfve spectfic conclusions about this distribution. But employing plausible qualitative conditions on the parameters, combined with assumptions on the relative varfances of the errors, we find limitations on the forms of the disequilibria that can arise. Depending on the specification used, one or two of the regimes can be proven to be much less 11kely than the others.

First one should note the obvious point that anticlpatory price setting makes the nature of the equilibrium independently determined from one period to the next.

Let us assume that the $\varepsilon^{\prime} s$ have mean zero and variances $\sigma_{1}^{2}, \sigma_{2}^{2}, \sigma_{3}^{2}$, $\sigma_{4}^{2}$ respectively. It is probably reasonable to expect that firms are more sensitive to constraints than are individuals. The permanent income hypothesis in its purest form would not leave any room for spillover effects in consumption or in labor supply. Firms, although infinttely lived in principal, do not allow their inventories to serve as a complete buffer when plans cannot be carried out. Some of the impact of sales constraints is to lower production, even in the short-run. Therefore we w1ll assume throughout the rest of this section that 


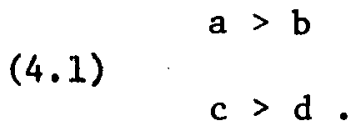

To derive the probabilities of the four regimes we use the inequality constraints defining them (2.11) - (2.14). These constraints can be written entirely in terms of $v_{t}^{1}=\varepsilon_{t}^{1}-\varepsilon_{t}^{2}$ and $v_{t}^{2}=\varepsilon_{t}^{3}-\varepsilon_{t}^{4}$.

\section{Independent Shocks}

The first specification of the errors that we will consider is the case in which they are independently distributed.

It is natural then to define

$$
\sigma_{v_{1}}^{2}=\sigma_{1}^{2}+\sigma_{2}^{2}
$$

$(4.2)$

$$
\sigma_{v_{2}}^{2}=\sigma_{3}^{2}+\sigma_{4}^{2}
$$

If In addition we postulate normality, then

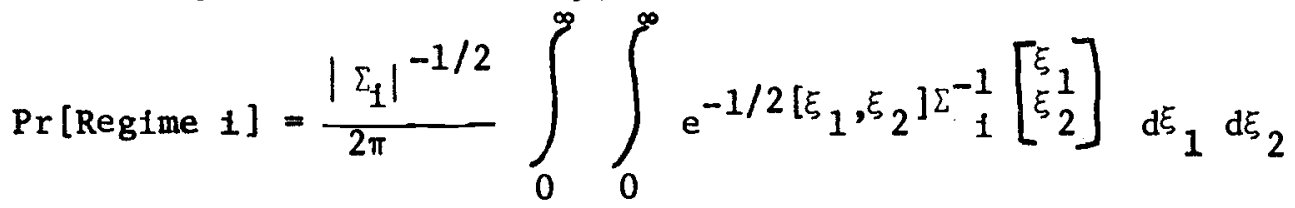

with

$$
\Sigma_{1}=\left[\begin{array}{cc}
\sigma_{v_{1}}^{2}+b^{2} \sigma_{v_{2}}^{2} & c \sigma_{v_{1}}^{2}+b \sigma_{v_{2}}^{2} \\
c \sigma_{v_{1}}^{2}+b \sigma_{v_{2}}^{2} & c \sigma_{v_{1}}^{2}+\sigma_{v_{2}}^{2}
\end{array}\right]
$$


$-23-$

$$
\begin{aligned}
& \Sigma_{2}=\left[\begin{array}{cc}
\sigma_{v_{1}}^{2}+a^{2} \sigma_{v_{2}}^{2} & -c \sigma_{v_{1}}^{2}-a \sigma_{v_{2}}^{2} \\
-c \sigma_{v_{1}}^{2}-a \sigma_{v_{2}}^{2} & c^{2} \sigma_{v_{1}}^{2}+\sigma_{v_{2}}^{2}
\end{array}\right] \\
& \Sigma_{3}=\left[\begin{array}{cc}
\sigma_{v_{1}}^{2}+a^{2} \sigma_{v_{2}}^{2} & d \sigma_{v_{1}}^{2}+a \sigma_{v_{2}}^{2} \\
d \sigma_{v_{1}}^{2}+a \sigma_{v_{2}}^{2} & d^{2} \sigma_{v_{1}}^{2}+\sigma_{v_{2}}^{2}
\end{array}\right] \\
& \Sigma_{4}=\left[\begin{array}{cc}
\sigma_{v_{1}}^{2}+b^{2} \sigma_{v_{2}}^{2} & -d \sigma_{v_{1}}^{2}-b \sigma_{v_{2}}^{2} \\
-d \sigma_{v_{1}}^{2}-b \sigma_{v_{2}}^{2} & d^{2} \sigma_{v_{1}}^{2}+\sigma_{v_{2}}^{2}
\end{array}\right]
\end{aligned}
$$

The probabilities of the different regimes can be ranked according

to the correlation coefficients, $\rho_{1}$ between $\xi_{1}$ and $\xi_{2}$ as specified by the matrices $\Sigma_{1}$.

$$
\begin{aligned}
& \rho_{1}^{\Sigma_{1}}=\frac{c_{v_{1}}^{2}+b \sigma_{v_{2}}^{2}}{\sqrt{\left(\sigma_{v_{1}}^{2}+b^{2} \sigma_{v_{2}}^{2}\right)\left(c^{2} \sigma_{v_{1}}^{2}+\sigma_{v_{2}}^{2}\right)}} \\
& \rho_{2}=-\frac{c \sigma_{v_{1}}^{2}+a \sigma_{v_{2}}^{2}}{\sqrt{\left(\sigma_{v_{1}}^{2}+a^{2} \sigma_{v_{2}}^{2}\right)\left(c^{2} \sigma_{v_{1}}^{2}+\sigma_{v_{2}}^{2}\right)}} \\
& \rho_{3}=\frac{d \sigma_{v_{1}}^{2}+a^{2} \sigma_{v_{2}}^{2}}{\sqrt{\left(\sigma_{v_{1}}^{2}+a^{2} \sigma_{v_{2}}^{2}\right)\left(d^{2} \sigma_{v_{1}}^{2}+\sigma_{v_{2}}^{2}\right)}} \\
& \rho_{4}=-\frac{d \sigma_{v_{1}}^{2}+b \sigma_{v_{2}}^{2}}{\sqrt{\left(\sigma_{v_{1}}^{2}+b^{2} \sigma_{v_{2}}^{2}\right)\left(d^{2} \sigma_{v_{1}}^{2}+\sigma_{v_{2}}^{2}\right)}}
\end{aligned}
$$


The highest probabilities are associated with the Keynesian unemployment (Regime 1) and repressed inflation (Regime 3) modes, where the correlations are positive. An intuition for this result can be derived from the observation that when errors occur one at a time only Regime 1 and 3 are possible. This point is due to the fact that the first effect of a shock is to constrain one agent (firms or consumers) in one market and by the spillover effect the other agent in the other market. The stability conditions imply that one remains then in a regime where both agents are constrafned, 1.e. efther Keyneslan unemployment or repressed inflation.

The comparison between Regimes 1 and 3 and between Regimes 2 and 4 is difficult and depends on the variances and on the splllover coeffictents. One possibility to obtain further results can be obtained if we are willing to make the assumption that shocks originating on the consumers' side of both markets are small compared to producers shocks.* This can be described by letting $\sigma_{v_{2}}^{2} / \sigma_{v_{1}}^{2}$ be small. Under these conditions $\rho_{1}$ and $\rho_{3}$ can be approximated as

$$
\begin{array}{r}
\rho_{1} \approx 1-(b-1 / c)^{2} \frac{\sigma_{v_{2}}^{2}}{\sigma_{v_{1}}^{2}} \\
\rho_{3} \approx 1-(a-1 / d)^{2} \frac{\sigma_{v_{2}}^{2}}{\sigma_{v_{1}}^{2}}
\end{array}
$$

Regime 1 will be more likely than Regime 3 if

$$
(a-1 / d)^{2}>(b-1 / c)^{2}
$$

This is the implicit assumption in much of Keynes and is made explicit in the work of Malinvaud. 
Even under the maintained hypotheses (4.1) this comparison could still go either way.

Three Cases of Non-Independent Shocks

We shall now consider three cases where the errors are interpreted as shocks to the technology and preferences of a particular form and are not, therefore, independent across the equations. Let us first consider firms. Suppose that there is a unit increase in labor demanded as the result of some factors exogenous to the model, for example a change in the tax rules governing employment. If the entire output of these workers is placed on the market, $x_{t}^{s}$ increases by $g$ - that is

$$
\varepsilon_{t}^{1}=g \varepsilon_{t}^{3}
$$

On the other extreme, the additional output could be divided between inventory accumulation and sales in the same proportion that would be caused by an involuntary rather than a voluntary shock to employment. Then one would have

$$
\text { (4.3) } \quad \varepsilon_{t}^{1}=a \varepsilon_{t}^{3} \text {. }
$$

Recal1 that $0<\mathrm{a}<\mathrm{g}$.

For individuals the argument is slightly more involved, but one obtains similar extreme cases as approximations. An exogenous increase of one unit in the level of labor offered to the market brings in a real income of $w_{t}-p_{t}$ in period $t$. Therefore the appropriate increase in demand for goods, under the hypothesis that all of this income is to be

To confirm the further intuition of Malinvaud that Keynesian unemployment is more likely than repressed inflation, one would have to invoke a bias of the price setting mechanism away from the anticipated Walrasian levels. 
spent, is $w_{t}-p_{t}$. Under this assumption, the relationship between the shocks to labor supply, $\varepsilon_{t}^{4}$, and goods demand, $\varepsilon_{t}^{2}$, depends on the prices prevaling in that perfod. This would make the analysis of the quantityconstrained equilibrium virtually as complex as the system with independent errors. It is more tractable if we take the approximation that $w_{t}-p_{t}$ is, In the long-run, equal to the real marginal product of labor $g$. This would give us

(4.4) $\quad \varepsilon_{t}^{2}=g \varepsilon_{t}^{4}$

which is analagous to (4.2). Alternatively, we can suppose that the extra earnings are divided between spending on goods and accumulation of money balances in the same proportion that the individual allocates his constrained labor income. Since one unit less of labor supply causes goods demand to drop by $b$, we obtain

$$
\text { (4.5) } \quad \varepsilon_{t}^{2}=b \varepsilon_{t}^{4} \text {. }
$$

It is possible to examine each of the four posstble combinations of these assumptions $(4.2)$ or $(4.3)$, together with either (4.4) or (4.5). To obtain the flavor of the analysis, however, we report on only three of these cases. We will see that the results are rather sensitive to this specification.

(4.2) and (4.5) : (Firms' shocks affect flows only, Individuals' shocks affect demands for money and goods)

The regimes are then defined by

$$
\begin{aligned}
\text { Regime } 1 \quad & (g-b) \varepsilon_{t}^{3}>0 \\
& (c g-1) \varepsilon_{t}^{3}+(1-b c) \varepsilon_{t}^{4}>0
\end{aligned}
$$

Regime $2(g-a) \varepsilon_{t}^{3}+(a-b) \varepsilon_{t}^{4}>0$

$$
(\mathrm{cg}-1) \varepsilon_{t}^{3}+(1-\mathrm{cb}) \varepsilon_{t}^{4}<0
$$


Regime $3(g-a) \varepsilon_{t}^{3}+(a-b) \varepsilon_{t}^{4}<0$

$$
(d g-1) \varepsilon_{t}^{3}+(1-b d) \varepsilon_{t}^{4}<0
$$

Regime $4 \quad(g-b) \varepsilon_{t}^{3}<0$

$$
(d g-1) \varepsilon_{t}^{3}+(1-b d) \varepsilon_{t}^{4}>0
$$

Then

$$
\begin{aligned}
& \rho_{1}=\frac{(c g-1) \sigma_{3}}{\left((c g-1)^{2} \sigma_{3}^{2}+(1-b c)^{2} \sigma_{4}^{2}\right)^{2}} \\
& \rho_{2}=-\frac{(g-a)(c g-1) \sigma_{3}^{2}+(a-b)(1-c b) \sigma_{4}^{2}}{\left(\left[(g-a){ }^{2} \sigma_{3}^{2}+(a-b)^{2} \sigma_{4}^{2}\right]\left[(c g-1)^{2} \sigma_{3}^{2}+(1-c b)^{2} \sigma_{4}^{2}\right]\right)^{\frac{1}{2}}}
\end{aligned}
$$

$(4.6)$

$$
\begin{aligned}
& \rho_{3}=\frac{(g-a)(d g-1) \sigma_{3}^{2}+(a-b)(1-b d) \sigma_{4}^{2}}{\left(\left[(g-a)^{2} \sigma_{3}^{2}+(a-b)^{2} \sigma_{4}^{2}\right]\left[(d g-1)^{2} \sigma_{3}^{2}+(1-b d)^{2} \sigma_{4}^{2}\right]\right)^{\frac{1}{2}}} \\
& \rho_{4}=-\frac{(d g-1) \sigma_{3}}{\left((d g-1)^{2} \sigma_{3}^{2}+(1-b d)^{2} \sigma_{4}^{2}\right)^{\frac{1}{2}}}
\end{aligned}
$$

Using (4.1) we find that $\rho_{1}<0: \rho_{4}>0, \rho_{2}$ and ${ }^{\prime}{ }_{3}$ being ambiguous. If the shocks on the consumer side are also smaller than on the producer side we have in general $\rho_{2}>0 \rho_{3}<0$, thus ranking Regimes 2 and 4, under consumption and classical unenployment, with the highest probability. If the shocks on the consumer side are greater (because of shocks in demand) we get $\rho_{2}<0$ and $\rho_{3}>0$. Repressed inflation and classical unemployment become the most 11 kely regimes. 
In summary, this specification of the shocks implies that Regime 4, Classical Unemployment, will be the most common occurrence,with Regimes 2 and 3, Underconsumption and Repressed Inflation occurring less frequently.

We now consider the case where none of the effects of the shocks impact upon the stocks of inventories or of money balances:

(4.2) and (4.4): (Both sectors' shocks affect only their notional demand for flows.)

This case is a good deal simpler than that studied above because it implies that $v_{t}^{1}=g v_{t}^{2}$. Since $v_{t}^{1}$ and $v_{t}^{2}$ completely determine the nature of the short-run equilibrium, as described in Section 2, the regimes are defined by
1. $\quad v_{t}^{1}-b v_{t}^{2}>0$
$c v_{t}^{1}-v_{t}^{2}>0$
2. $\quad v_{t}^{1}-a v_{t}^{2}>0$
$c v_{t}^{1}-v_{t}^{2}<0$
3. $\quad v_{t}^{1}-a v_{t}^{2}<0$
$d v_{t}^{1}-v_{t}^{2}<0$
4. $\quad v_{t}^{1}-b v_{t}^{2}<0$
$d v_{t}^{1}-v_{t}^{2}>0$

Using $\mathrm{v}_{\mathrm{t}}^{1}=\mathrm{g} \mathrm{v}_{\mathrm{t}}^{2}$ and the conditions $0<\mathrm{a}<\mathrm{g}, 1 / \mathrm{c}>\mathrm{g}>0,0<\mathrm{b}<\mathrm{g}$, and $1 / \mathrm{d}>\mathrm{g}>0$, we find that only Regimes 2 and 4 , that is only Underconsumption and classical unemployment, are possible. Note that no assumption was made here about the relative size of the variances $\sigma_{v_{1}}^{2}$ and $\sigma_{v_{2}}^{2}$, and indeed the probabilities of the regimes would be invariant to such a specification, given our assumption that money balances and inventories are insulated from the shocks.

Finally we look at the case in which both sectors allocate the shock between the stock they control and current notional demands in the same proportion as they would for a constraint on their trades. 
(4.3) and (4.5): (Both sectors' shocks affect notional demands for flows and stocks.)

Substituting into the basic definftions of the regimes we obtain their dependence on $\varepsilon_{t}^{3}$ and $\varepsilon_{t}^{4}$ in this case:

$$
\begin{aligned}
& \text { 1. } \quad(a-b) \varepsilon_{t}^{3}>0 \\
& -(1-a c) \varepsilon_{t}^{3}+(1-b c) \varepsilon_{t}^{4}>0 \\
& \text { 2. } \quad(a-b) \varepsilon_{t}^{4}>0 \\
& -(1-a c) \varepsilon_{t}^{3}+(1-b c) \varepsilon_{t}^{4}<0 \\
& \text { 3. } \quad(a-b) \varepsilon_{t}^{4}<0 \\
& \quad-(1-a d) \varepsilon_{t}^{3}+(1-b d) \varepsilon_{t}^{4}<0 \\
& \quad(a-b) \varepsilon_{t}^{3}<0 \\
& \quad-(1-a d) \varepsilon_{t}^{3}+(1-b d) \varepsilon_{t}^{4}>0 .
\end{aligned}
$$

If we assume that $\sigma_{v_{2}}^{2} / \sigma_{v_{1}}^{2}$ is small we find that Regime 1 has a vanishingly small probability and that Regime 4 will occur whenever $\varepsilon_{t}^{3}<0$. With $\varepsilon_{t}^{3}>0$, the sign of $\varepsilon^{4}$ determines whether we are in Regime 2 or 3 . Therefore the appropriate probabilities of Regimes 2, 3, and 4 are $1 / 4,1 / 4$, and $1 / 2$ respectively.

The case of $\sigma_{v_{1}}^{2} / \sigma_{v_{2}}^{2}$ small, which admittedly has little support in the literature, would yield asymptotically the probabilities $(1 / 4,0,1 / 2,1 / 4)$ for the four regimes respectively. Combining these results we see that Regimes 3 and 4 are going to be more likely than Reglmes 1 and 2, whatever the error structure is. The goods market is systematically more likely to be in excess supply than in excess demand! 
We can see, therefore, that the nature of the shocks is an important determinant of the probability of reaching any of the regimes. If direct evidence were avaflable as to the nature of the binding quantity constraints at different points in time, ${ }^{*}$ indirect evidence would be avallable as to the relative magnitude of the shocks. the labor market. Evidence in the goods market is harder to ascertain since intended inventory movements may be confounded with flow disequilibrium. 


\section{Dynamic Behavior of Quantity-Constrained Equilibrium Process}

In this section we will utilize the stochastic structure derived above to study the dynamics of inventories, employment, output, the real wage and correlations among them. We will compare the results of the disequilibrium model to those arising from a system where prices are flexible after the realization of the shocks, as described in Section 3 . In particular we will ask whether or not these systems are "observationally equivalent", and we will suggest methods for testing one of these hypotheses against the other.

The dynamics of inventories

In this model inventories are entirely composed of unsold stocks of final goods. Because there is no depreciation, the change in stocks is simply the difference between production and sales. The evolution of inventories is described by

(5.1) $\quad s_{t+1}=s_{t}+g l_{t}-x_{t}$

Equation (5.1) is a stochastic difference equation because $\ell_{t}$ and $x_{t}$ are random variables that depend on the underlying $\varepsilon^{\prime} s$, and on the current value of $s_{t} \cdot$ Recognizing this dependence explicitly, we obtain a relation that is piecewise linear in the $\varepsilon_{t^{\circ}}$. 
(5.2) $\quad\left(s_{t+1} s_{t}\right)=g L_{t}-x_{t}+ \begin{cases}\frac{\varepsilon_{t}^{1}(b-g) c+\varepsilon_{t}^{2}(b c-1)+\varepsilon_{t}^{3}(g-b)+\varepsilon_{t}^{4} b(1-c g)}{1-b c} & \text { Regime 1 } \\ -\varepsilon_{t}^{2}+g \varepsilon_{t}^{4} & \text { Regime 2 } \\ \varepsilon_{t}^{1}(g d-1)+\varepsilon_{t}^{2} d(a-g)+\varepsilon_{t}^{3} a(1-g d)+\varepsilon_{t}^{4}(g-a) & \text { Regime } 3 \\ -\varepsilon_{t}^{1}+g \varepsilon_{t}^{3} & \text { Regime 4 }\end{cases}$

Let $\phi^{i}\left(\varepsilon_{t}\right)$ denote the linear form in the $\varepsilon$ associated with regime 1 , in equations (5.2), $i=1,2,3,4$.Consider the anticipated change in inventory stocks, that is, the change that would happen if all the $\varepsilon^{\prime} s$ were zero and prices were set as we have postulated.

$$
g_{t}^{L}-X_{t}=\frac{\left(g \delta_{1}-\beta_{1}\right)\left[\alpha_{0}\left(\delta_{2}+\gamma_{1}\right)-\gamma_{0}\left(\beta_{2}+\alpha_{1}\right)\right]+\left(g \delta_{2}-\beta_{2}\right)\left[\gamma_{0}\left(\beta_{1}-\alpha_{1}\right)-\alpha_{0}\left(\delta_{1}-\gamma_{1}\right)\right]}{\left(\beta_{1}-\alpha_{1}\right)\left(\delta_{2}+\gamma_{1}\right)-\left(\delta_{1}-\gamma_{1}\right)\left(\beta_{2}+\alpha_{1}\right)}\left(s_{t}-\bar{s}\right)
$$

Let us define the coefficient on the right hand stde to be $\mathrm{K}_{0}$, a function only of the parameters of the system. $K_{0}$ is the effect on the anticipated change in inventories due to one unit of additional initial stocks. When $\delta_{1}$ and $\delta_{2}$ are small, it can be verified that $1>K_{0}>0$ and hence that the process is stable.

We can express the dynamics of inventories in a succint way by defining the function $\phi\left(\varepsilon_{t}\right)$ to have the value of $\phi^{i}\left(\varepsilon_{t}\right)$ whenever $\varepsilon_{t}$ lies in regime 1 . Thus $\phi\left(\varepsilon_{t}\right)$ is defined over the whole range of $\varepsilon_{t}$. In this notation

$$
\left(s_{t+1}-\bar{s}\right)=\left(1+k_{0}\right)\left(s_{t}-\bar{s}\right)+\phi\left(\varepsilon_{t}\right)
$$

or 


$$
s_{t+1}=k_{0} \bar{s}+\left(1+k_{0}\right) s_{t}+\phi\left(\varepsilon_{t}\right)
$$

Equation (5.4) can now be analyzed under a variety of conditions corresponding to particular assumptions on the joint distribution of $\varepsilon_{t}$. As the detalls are straightforward, we will only summarize the results here.

If the four shocks are independent, little can be said in general about the Markov process defined by (5.4). The mean value of the error term averaged over the four regimes will not be zero because they enter In a plecewise linear, rather than a linear, fashion. Therefore the longrun average for $s_{t}$ will be biased away from 1 ts target $\bar{s}$.

It is interesting to ask whether the time series behavior of inventories can be used to distinguish between this model and the equilibrium model of Section 3 .

Using (3.1), (3.2) and (3.3) we can see that in the equilibrium stock adjustment equation will be of the same general form as (5.5) but the errors enter linearly. This suggests the following test of the equilibrium mode1.

Write the equilibrium model as

$$
s_{t+1}=k_{0}^{e q} \bar{s}+\left(1+k_{0}^{e q}\right) s_{t}+\phi^{e q}\left(\varepsilon_{t}\right)
$$

paralleling the notation of (5.5). The error term will have mean zero.

If this equation were estimated, $\mathrm{K}_{0}{ }^{\mathrm{eq}} \mathrm{s}$ would be the value of the constant. Moreover, if the data were partitioned into various subsets, the same constant would be consistantly estimated in each of them. This should be contrasted with the case of disequilibrium as in (5.5). If the data were partitioned according to the varfous regimes, a different constant, namely $K_{0}^{e q} \bar{s}+E \phi^{1}\left(\varepsilon_{t}\right)$, with 
the expectation conditioned on regime 1 , would be observed in each regime.

of course it is not obvious at all which regime is operative at which point. Unlike previous work in disequilibrium econometrics, the direction of the price change in our model does not indicate anything about the effective quantity constraints. Therefore the brute force procedure would be to estimate the disequilibrium system by maximum likelihood methods separately for each of the $4^{\mathrm{T}}$ partitions of the $\mathrm{T}$ data points, allowing a different constant in each regime, and then to perform a likelihood ratio test of the overall maximum likelihood among these regressions against the equation estimated with a single constant.

of course if $\mathrm{T}$ is fairly large this method becomes impractical. Some economies of computation are possible, however, under more restrictive hypotheses about the joint distribution of the components of $\varepsilon_{t}$.

With the assumption that shocks do not impinge upon the notional inventory, but that individuals divide shocks between money balances and flow demands, (4.2) and (4.5), we can derive from (5.2) that $\mathrm{E}^{1}\left(\varepsilon_{t}\right)>0$, $\mathrm{E} \phi^{2}\left(\varepsilon_{t}\right)=0, E \phi^{3}\left(\varepsilon_{t}\right)<0$ and $E \phi^{4}\left(\varepsilon_{t}\right)=0$ (indeed $\phi^{4}\left(\varepsilon_{t}\right) \equiv 0$ ). These qualitative constraints can be used to check the maximum likelihood estimations of the four regimes: the estimated constants in Regime 1 exceed those of Regimes 2 and 4 which in turn exceed that in Regime 3. Moreover these constraints can provide an algorithm for partitioning the data, if (4.2) and (4.5) are adopted as maintained hypotheses. For example, if $\sigma_{3}^{2}$ is thought to dominate $\sigma_{4}^{2}$, we know from (4.6) that Regimes 2 and 4 become far more likely than 1 and 3 . We might therefore begin by running the unconstrained regression (5.5), ignoring the biased error term, and then assign that half of the data with the largest residuals to Regime 4 and the others to Regime 2 .*

\footnotetext{
This method is reminiscent of the Fair - Jaffee (1972) procedure.
} 
Another case of interest, paralleling the treatment of the last section, occurs where the shocks affect current notional demands and desired stocks in the same proportion as would quantity constraints: (4.3) and (4.5).

We have from (5.2) that

$(5.7)$

$$
\begin{aligned}
& \phi^{1}\left(\varepsilon_{t}\right)=(g-b)(1-a c) \varepsilon_{t}^{3}+(1-c g) b \varepsilon_{t}^{4} \\
& \phi^{2}\left(\varepsilon_{t}\right)=(g-b) \varepsilon_{t}^{4}
\end{aligned}
$$

$$
\begin{aligned}
& \phi^{3}\left(\varepsilon_{t}\right)=(g-a)(1-b d) \varepsilon_{t}^{4} \\
& \phi^{4}\left(\varepsilon_{t}\right)=(g-a) \varepsilon_{t}^{3}
\end{aligned}
$$

Recalling the results on the probability distribution over these regimes when $\sigma^{2} v_{2} / \sigma_{v_{1}}^{2}$ is small we know that Regime 1 is not possible, and Regimes 2, 3, and 4 occur approximately whenever $\varepsilon^{3}>0$ and $\varepsilon^{4}>0$, $\varepsilon^{3}>0$ and $\varepsilon^{4}<0$, and $\varepsilon^{3}<0$ respectively. From (5.7) we see that the biases induced in the constants in Regimes 2 and 3 will be small, since $E \varepsilon^{4} \mid \varepsilon^{4}>0$ is small compared to $\mathrm{E} \varepsilon^{3} \mid \varepsilon^{3}<0$. Thus an pproximate test of the disequilibrium model under the maintained hypotheses $(4.3),(4.5)$, is to segregate the data into two subsets, presumably those in or out of Regime 4, and test for the inequality of the constants in these separate regressions. (Of course this will be a weaker test than the full maximum likelihood procedure, but the computational advantages may be significant.)

Other combinations of $(4.2)(4.3)$ and $(4.4)(4.5)$ can be studied with similar results.

Correlation between real wages and inventories

In the disequilibrium model we have studied, the anticipatory nature of the price adjustment process makes the real wage a function of inventories 
alone. Therefore, in the absence of observational errors, a perfect (negative) correlation between them would be observed.

The equilibrium model's real wage is given by (3.1). It is easy to show that the coefficient of $\left(s_{t}-\bar{s}\right)$ is the same in this equation as it is in the disequilibrium theory. The two differ only in the presence of the error term. Because of observational errors, however, we cannot discriminate between them.

\section{Correlation between employment and inventories}

In the disequilibrium model the realized levels of employment are given by

$(5.8) \ell_{t}=L_{t}+ \begin{cases}\frac{-c\left(\varepsilon_{t}^{1}-\varepsilon_{t}^{2}\right)+\left(\varepsilon_{t}^{3}-b c \varepsilon_{t}^{4}\right)}{1-b c} & \text { Regime } 1 \\ \frac{d\left(\varepsilon_{t}^{1}-\varepsilon_{t}^{2}\right)-a d \varepsilon_{t}^{3}+\varepsilon_{t}^{4}}{1-a d} & \text { Regime 2 } \\ \frac{\varepsilon_{t}^{3}}{\varepsilon_{t}} & \text { Regime 4 }\end{cases}$

The dependence of $\mathrm{L}_{t}$, anticipated employment if there are no shocks, on inventories can be computed from (1.21), (1.22) and (1.23) to be:

$$
L_{t}=\frac{\gamma_{0}\left[\delta_{2}\left(\beta_{1}-\alpha_{1}\right)-\delta_{1}\left(\beta_{2}+\alpha_{1}\right)\right]+\alpha_{0}\left[\delta_{1}+\delta_{2}\right] \gamma_{1}}{\Delta}\left(s_{t}-\bar{s}\right)
$$


In the equilibrium model employment is given by (3.2). Note that the systematic dependence of employment on inventories is the same under either theory.

As in the case of the autocorrelation of the inventory series, the difference lies in the stochastic structure. Different constant terms in the regressions within each regime would provide evidence for the disequilibrium hypothesis.

We will not elaborate upon the possibilities under all the stochastic specifications treated previously. It is useful, however, to examine one of them again because it indicates how a combination of evidence on inventories and employment can help identify regimes and provide a sharper discrimination between these theories.

Consider the case of (4.3) and (4.5), where disturbances impinge upon notional demand for stocks in both sectors. The relations (5.8) become:

$$
\ell_{t}=B_{t}+ \begin{cases}\frac{(1-a c)}{1-b c} \varepsilon_{t}^{3} & \text { Regime 1 } \\ \varepsilon_{t}^{4} & \text { Regime 2 } \\ \varepsilon_{t}^{4} & \text { Regime 3 } \\ \varepsilon_{t}^{3} & \text { Regime 4 }\end{cases}
$$

Compare these errors to the analagous terms in the inventory dynamics equation (5.7). When $\sigma_{v_{2}}^{2} / \sigma_{v_{1}}^{2}$ is small, the sign of the errors in each of the three possible regimes is precisely the same in (5.9) as it is in (5.7). Therefore, if we identify a particular partition of the data points for one equation, then under the maintained hypotheses about the errors, the constants 
estimated by maximum likelihood from the other equation should stand in the same relationship across the regimes when the data are partitioned the same way.

Indeed a further check is possible, using the fact that $\sigma_{v_{2}}^{2} / \sigma_{v_{1}}^{2}$ is sma11. We can neglect the difference between the constants estimated in Regimes 2 and 3 compared with their relation to that in Regime 4 . From (5.9) and (5.7) we can see that the difference between Regime 4 and the other two in the employment regressions is $E \varepsilon_{t}^{3} \mid \varepsilon_{t}^{3}<0$, and in the inventory autoregression it is $(\mathrm{g}-\mathrm{a}) \mathrm{E} \varepsilon_{\mathrm{t}}^{3} \mid \varepsilon_{\mathrm{t}}^{3}<0$. We can infer that the crossequation difference in the constants in the inventory autoregression should be less than $g$ times the bias in the employment regressions, because a $>0$. (The productivity of labor, $\mathrm{g}$, can be estimated as the average real wage, so this procedure is well-defined.)

Correlation between real wages and employment

Both the disequilibrium and equilibrium models predict a negative correlation between real wages and employment when $\left(\delta_{1}+\delta_{2}\right)$ is relatively small. Tests based on the stochastic structure similar to those described above can be constructed, but we believe that they will be harder to use . There are difficulties in constructing a real wage series corrected for the changing composition of the labor force and the problem of obtaining wage rates when overtime and other considerations distort the relationship between hours of employment and total earnings. 


\section{Appendix}

We gather together a few regression results that are related to the results of this paper. No attempt is made to give a detailed treatment of problems in structural estimation of macroeconomic systems. These results should be viewed merely as exploring some correlations in the data, and not as necessarily confirming or disproving specific hypotheses.

Nevertheless we believe they are of interest. In particular they point out the strong influence of inventories on the real wage.

The variables used are:

$W$, wage The real wage in the manufacturing sector. Computed as the ratio of hourly earnings to the implicit price deflator for personal consumption expenditures.

$\mathrm{H}$, hours The measure of total manufacturing employment. Computed as the product of weekly hours for production workers with total employment in the manufacturing sector.

INV, inventories Total inventories in the manufacturing sector.

IMP, import price

index Index of unit-values of imported goods.

Al1 data are seasonally adjusted.

We present three sets of regressions for monthly, quarterly and annual

data. In accordance with the theory, we treat as exogenous the initial level of inventories.

In the monthly regressions we use the previous month's value. In both quarterly and annual regressions we use the value associated with the last month of the previous time period.

The wage, hours inventories and import prices are used in logarithms, time is not used as a logarithm. 
Month1y

(1) $\mathrm{W}=1.58-0.095 \mathrm{Lag}$ INV $+.0018 \mathrm{~T}+3.5 \times 10^{-6} \mathrm{~T}^{2}-0.11$ IMP $(12.6) \quad(-3.1) \quad(8.7) \quad(3.4) \quad(-4.7)$

corrected for first-order autocorrelation: $\rho=.82$

$\bar{R}^{2}=.996 \quad \mathrm{DW}=1.95$

(2) $\mathrm{W}=1.70-0.123 \mathrm{Lag} \mathrm{INV}+.002 \mathrm{~T}+6.0 \times 10^{-6} \mathrm{~T}^{2}$ (9.3) (-2.7) (.05)

corrected for first-order autocorrelation: $p=.91$

$\overline{\mathrm{R}}^{2}=.995 \quad \mathrm{DW}=1.94$

(3) $\quad \mathrm{H}=7.56-0.250 \mathrm{Lag} \mathrm{INV}+.0039 \mathrm{~T}-3.6 \times 10^{-6} \mathrm{~T}^{2}-0.17 \mathrm{IMP}$ $\begin{array}{llll}(9.1) \quad(-1.2) & (2.5) \quad(-.49) \quad(-1.4)\end{array}$

corrected for second-order autocorrelation: $\rho_{1}=\underset{(15.7)}{1.2}, \rho_{2}=\frac{-.227}{(-2.9)}$

$\overline{\mathrm{R}}^{2}=.966 \quad \mathrm{DW}=2.08$

(4) $\mathrm{H}=7.91-0.332 \mathrm{Lag} \mathrm{INV}+.0042 \mathrm{~T}-7.8 \times 10^{-6} \mathrm{~T}^{2}$ (11.1) $(-1.9) \quad(2.8) \quad(-1.0)$

corrected for second-order autocorrelation: $\rho_{1}=\underset{(15.8)}{1.2}, \rho_{2}=\frac{-.228}{(-2.9)}$

$\overline{\mathrm{R}}^{2}=.966 \quad \mathrm{DW}=2.08$

\section{Quarterly}

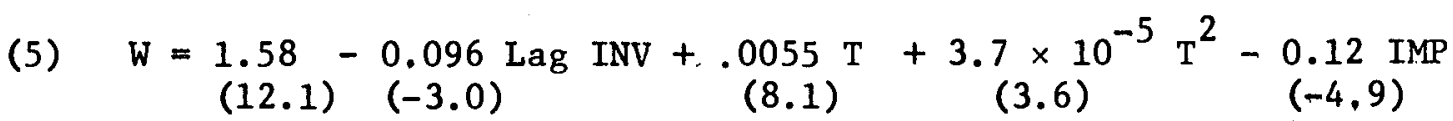

corrected for first-order autocorrelation: $\rho=.63$

$\bar{R}^{2}=.992 \quad \mathrm{DW}=1.96$ 
(6) $\mathrm{W}=1.77-0.141 \mathrm{Lag} \mathrm{INV}+.0062 \mathrm{~T}+3.5 \times 10^{-6} \mathrm{~T}^{2}$

$$
\text { (9.3) (-3.0) (5.5) (.28) }
$$

corrected for first-order autocorrelation: $\rho=.80$

$\overline{\mathrm{R}}^{2}=.990 \quad \mathrm{DW}=1.74$

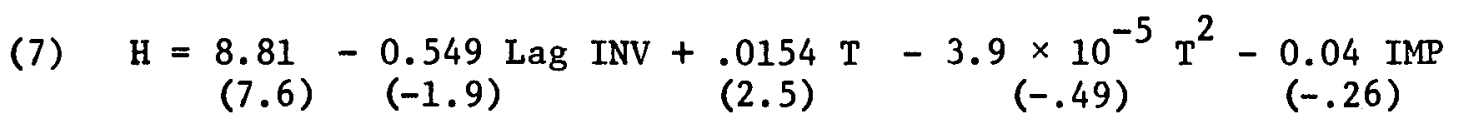

corrected for second-order autocorrelation: $\rho_{1}=\underset{(10.9)}{1.46}, \rho_{2}=\frac{-0.54}{(-4.3)}$

$\bar{R}^{2}=.911 \quad \mathrm{DW}=2.05$

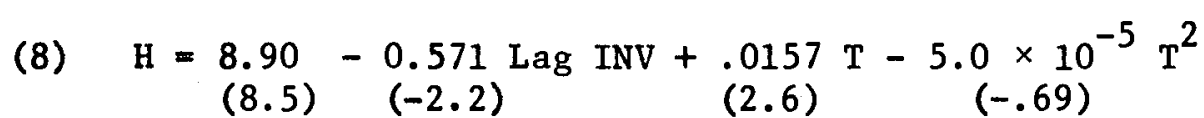

corrected for second-order autocorrelation: $\rho_{1}=\underset{(11.2)}{1.36}, \quad \rho_{2}=\underset{(-4.4)}{-0.55}$

$\overline{\mathrm{R}}^{2}=.913 \quad \mathrm{DW}=2.04$

Annual

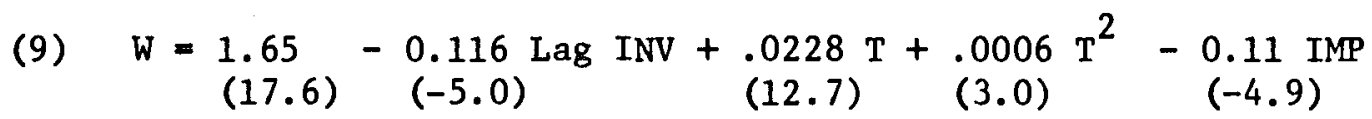

corrected for second-order autocorrelation: $\rho_{1}=-0.48, \rho_{2}=-0.46$

$\overline{\mathrm{R}}^{2}=.991 \quad \mathrm{DW}=2.43$

(10) $\mathrm{W}=\underset{(8.0)}{1.71} \underset{(-2.4)}{0.129} \mathrm{Lag} \mathrm{INV}+\underset{(5.7)}{.025 \mathrm{~T}}-\underset{(-.47)}{9.3 \times 10^{-5}} \mathrm{~T}^{2}$

$\overline{\mathrm{R}}^{2}=.970 \quad \mathrm{DW}=1.69$

(11) $\mathrm{W}=1.71-0.128 \mathrm{Lag} \mathrm{INV}+.025 \mathrm{~T}-7.5 \times 10^{-5} \mathrm{~T}^{2}$

$(6.0) \quad(-1.8) \quad(4.0) \quad(-.33)$

corrected for first-order autocorrelation: $\rho=0.10$

$(0.2)$

$\overline{\mathrm{R}}^{2}=.966 \quad \mathrm{DW}=1.77$ 
(12) $\mathrm{W}=\underset{(6.4)}{1.24} \underset{(-.32)}{-0.015} \mathrm{Lag} \mathrm{INV}+\underset{(5.6)}{.0202} \mathrm{~T}-\underset{(-2.4)}{.0004 \mathrm{~T}^{2}}$

corrected for second-order autocorrelation: $\rho_{1}=\underset{(1.3)}{0.33}, \rho_{2}=\underset{(-4.5)}{-0.81}$ $\overline{\mathrm{R}}^{2}=.982 \quad \mathrm{DW}=2.25$

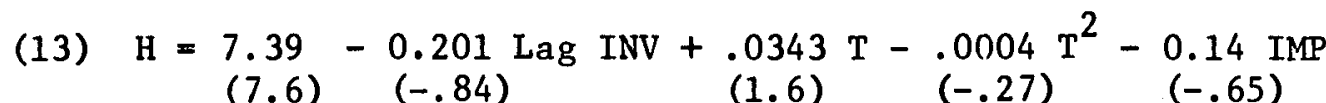
$\overline{\mathrm{R}}^{2}=.045 \quad \mathrm{DW}=1.17$

(14) $\mathrm{H}=8.54-0.494 \mathrm{Lag} \mathrm{INV}+.056 \mathrm{~T}-.0006 \mathrm{~T}^{2}-0.10 \mathrm{IMP}$ $\begin{array}{llll}(5.8) \quad(-1.4) & (2.2) \quad(-.34) \quad(-.34)\end{array}$

Corrected for first-order autocorrelation: $\rho=.62$ $\overline{\mathrm{R}}^{2}=.202 \quad \mathrm{DW}=1.09$

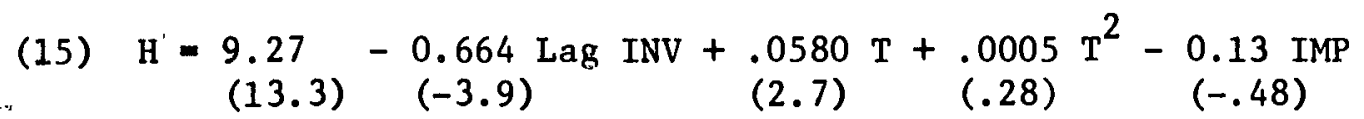
corrected for second-order autocorrelation: $\rho_{1}=\underset{(4.6)}{1.18}, \rho_{2}=\frac{-0.77}{(-3.2)}$ $\overline{\mathrm{R}}^{2}=.615 \quad \mathrm{DW}=1.61$

(16) $\mathrm{H}=\underset{(8.6)}{8.72} \underset{(-2.2)}{-0.537} \mathrm{Lag} \mathrm{INV}+\underset{(2.62)}{.0632 \mathrm{~T}}-\underset{(-.69)}{.0010 \mathrm{~T}^{2}}$ corrected for first-order autocorrelation: $\rho=0.65$ $\overline{\mathrm{R}}^{2}=.280 \quad \mathrm{DW}=1.03$

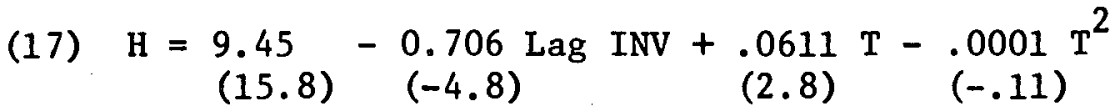
corrected for second-order autocorrelation: $\rho_{1}=\underset{(5.1)}{1.23}, \rho_{2}=\underset{(-3.7)}{-0.77}$ $\overline{\mathrm{R}}^{2}=.654 \quad \mathrm{DW}=1.66$ 
Summary of Results

The principal reason for performing three separate types of regresstons 1s that we do not know the timing of the anticfpatory pricing and the shocks which are supposed to be accomodated by disequilibrium quantity adjustments. No attempt was made to search for regressions with more explanatory power, but we do present two forms of the equations according to whether the import price index variable is included. It was felt that this variable Is largely exogenous and that it exerts a strong influence on prices and output quite independent of the inventory situation. 
References

Barro, R.J. and H.I. Grossman [1971], "A General Disequilibrium Model of Income and Employment,". American Economic Review, vol. 71, 250-272.

Benassy, J.P. [1975], "A Neo-Keynesian Disequilibrium In a Monetary Economy," Review_of Economic Studies, vo1.42, 503-524.

Blinder, A. [1:77], "A Difriculty with Keyncsian Models of Afgregate Demand," in Natural Resources, Uncertainty and Genera1 Equilibrium Systems, essays in memory of Rafael Lusky, Academic Press, Inc.

Blinder, A. [1978], "Inventories in the Keynesian Macro Model," mimeographed, Princeton University.

Blinder, A.S. and S. Fischer [1979], "Inventories, Rational Expectations, and the Business Cycle," National Bureau of Economic Research, Working Paper No. 381.

Drèze, J.H. [1975], "Existence of an Exchange Equilibrium Under Price Rigidities," Internationa1 Economic Review, vol.16, 301-320.

Fatr, R. and D.M. Jaffec [1972], "Methods of Estimation for Markets In Disequilibrium," Econometrica, vo1.40, 497-514.

Fair, R.C. and D.M. Jaffee [1976], "Methods of Estimation for Markets in Disequilibrium: A Further Study," Econometrica, vol.42, 177-190. Gourieroux, C., J.J. Laffont and A. Monfort [1978], "Disequilibrium Ecorometrics in Simultaneous Equation Systems," I.M.S.S.S. report Stanford University, Econometrica forthcoming.

Gourieroux, C., J.J. Laffont and A. Monfort [1979], "Coherency Conditions in Simultaneous Linear Equation Models with Endogenous Switching Regimes," N.B.E.R. Working Paper No. 343, forthcoming in Econometrica. Ionlapohfa, S. [1079], "On the Nynanics of Disenut? fbrium in a Macro Model with Flexible Wages and Prices," in M. Aoki and A. Marzollo (eds.), New Trends in Dynamic System Theory and Economics, Academic Press. 
Laffont, J.J. and R. Garcia [1974], "Disequilibrium Econometrics for Business Loans," Econometrica, vo1.45, 1187-1204.

Malinvaud, E. [1977], The Theory of Unemployment Reconsidered, 0xford: Bas11, Blackwell.

Muellbauer, J. and R. Portes [1978], "Macroeconomic Models with Quantity Rat loning," Economic Journal, vol. 88, 788-821. 

Laffont, J.J. and R. Garcia [1974], "Disequilibrium Econometrics for Business Loans," Econometrica, vol.45, 1187-1204.

Malinvaud, E. [1977], The Theory of Unemployment Reconsidered, Oxford: Bas11, Blackwel1.

Muel1bauer, J. and R. Portes [1978], "Macroeconomic Models with Quantity Rationing," Economic Journal, vol. 88, 788-821. 